\title{
Title
}

\section{Biology of ferritin in mammals: an update on iron storage, oxidative damage and} neurodegeneration.

Dario Finazzi ${ }^{1,2}, \mathrm{MD}$ and Paolo Arosio, $\mathrm{PhD}^{1}$

1 Department of Molecular and Translational Medicine, University of Brescia, Viale Europa 11, 25123 Brescia, Italy

2 Spedali Civili di Brescia, P.le Spedali Civili, 1, 25123 Brescia, Italy

Corresponding Author

Dario Finazzi

Department of Molecular and Translational Medicine, University of Brescia, Viale Europa 11, 25123 Brescia, Italy

Phone ++390303717334

Fax ++390303717305

Email dario.fianzzi@unibs.it

\begin{abstract}
Iron is an abundant transition metal that is essential for life, being associated to many enzyme and oxygen carrier proteins involved in a variety of fundamental cellular processes. At the same time the metal is potentially toxic due to its capacity to engage in the catalytic production of noxious reactive oxygen species. The control of iron availability in the cells is largely dependent on ferritins, ubiquitous proteins with storage and detoxification capacity. In mammals, cytosolic ferritins are composed of two types of subunits, the $\mathrm{H}$ and the $\mathrm{L}$ chain, assembled to form a 24-mer spherical cage. Ferritin is present also in mitochondria, in the form of a complex with 24 identical chains. Even though the proteins have been known for a long time, their study is a very active and interesting field yet. In this review we will focus our attention to mammalian cytosolic and mitochondrial ferritins, describing the most recent advancement regarding their storage and antioxidant function, the effects of their genetic mutations in human pathology, and also the possible involvement in non-iron related activities. We will also discuss recent evidence connecting ferritins and the toxicity of iron in a set of neurodegenerative disorder characterized by focal cerebral siderosis.
\end{abstract}

\section{Introduction}

The adaptation of life to an oxic environment required the development of mechanisms to deal with the transformation of the water soluble ferrous ion $\left(\mathrm{Fe}^{2+}\right)$ to the insoluble ferric ion $\left(\mathrm{Fe}^{3+}\right)$ and with the concomitant generation of dangerous reactive oxygen species (ROS). The ferritin molecules represent an important and ancient mean developed by organisms in the three domains of life to safely handle the necessary, yet potentially toxic metal. Their ability to detoxify and store the metal through safe oxidation processes protects the cells from undue iron-dependent redox chemistry, while a controlled release of the metal guarantees its availability for different and essential enzymatic reactions. Storage and detoxification of iron represent the main functions of these molecules, and much work has been done to understand the chemical and molecular details of this 
processes in the different types of ferritins, the classical ones, the heme-containing bacterioferritins and the smaller docecameric Dps proteins. These findings have been described in various excellent reviews of the recent years (Arosio and Levi 2010; Bou-Abdallah 2010; Theil 2013), but the interest in ferritin is not fading and new interesting data are continuously appearing. In this review we focus our attention to the mammalian ferritins and their possible involvement in the perturbation of iron homeostasis often observed in neurodegenerative disorders. Interestingly, there is mounting evidence that mammalian ferritins can also exert functions not related to the iron storagedetoxification processes. We will discuss this novel and unexpected activities and their potential significance for human physiopathology.

\section{Mammalian ferritin structure}

In mammalian ferritins, 24 subunits assemble to form a hollow symmetrical protein with a molecular weight of about $480 \mathrm{kDa}$; the multimer is a shell with an outer diameter of $12 \mathrm{~nm}$ limiting a 8-nm diameter cavity that can accommodate up to 4500 iron atoms. Structural analysis shows that the protein cage is composed by dimers arranged with a 4,3,2 symmetry with 8 hydrophilic pores at the connection of three subunits, and 6 hydrophobic channels at the connection of four subunits (figure 1). In each subunit most of the amino acid residues are within $5 \alpha$-helix secondary structures, identified as A, B, C, D and E and a long loop between B and C helices. Helixes A to D constitute the common and roughly cylindrical four-helical bundle structural motif (Punta et al. 2012) (figure 2) characterizing the many proteins belonging to the Ferritin-like superfamily (Andrews 2010), whereas the $5^{\text {th }}$ helix E stems from one end of the bundle with an angle of about $60^{\circ}$. The helixes $\mathrm{A}$ and $\mathrm{C}$, together with the unstructured $\mathrm{NH}_{2}$-terminus and the long $\mathrm{B}-\mathrm{C}$ loop are exposed to the outside of the protein, whereas the $\mathrm{B}$ and $\mathrm{D}$ helices are buried inside it. Three different type of monomer are in mammalian cells: the $\mathrm{H}(\mathrm{FtH}$, heart/heavy, $\sim 21 \mathrm{kDa}$ ) and $\mathrm{L}$ (FtL, liver/light, $\sim 19 \mathrm{kDa}$ ) monomers are constituents of the ubiquitous and most abundant cytosolic ferritins, while the mitochondrial subunit (FtMt, $\sim 21 \mathrm{kDa}$ ) is found exclusively in the mitochondrial ferritin. RNAs potentially coding for other types of ferritin subunits have been identified (FtH-L17), but no protein products have been associated with them so far (Wang et al. 2001). The three monomers show high level of homology but only FtH and FtMt conserve the amino acids required for the formation of a di-iron ferroxidase center, buried inside the $\alpha$-helix bundle, that catalyzes the oxidation from ferrous to ferric iron necessary for iron deposition in the cavity (figure 3A and B) (Harrison and Arosio 1996). On the contrary, the L-subunit presents a nucleation site, a cluster of cavity-exposed carboxyl residues that can bind Fe(III) ions, that facilitates iron nucleation and hydrolysis, the late steps of core formation (Santambrogio et al. 1996). Thus, the presence of both chains in the cytosolic ferritin is associated with improved storage functionality. The assembly of the $\mathrm{H}$ and $\mathrm{L}$ subunits into the 24-mer cytosolic shell produces a variety of different molecules (isoferritins) (Drysdale et al. 1977) differing for the relative abundance of each monomer. This depends on the type of tissue and also on the pathophysiological conditions. Tissues with a main storage function (liver, spleen) contain L-rich (up to 90\%) ferritins, that are more stable and may contain more iron, while those with high iron oxidation activity (heart, brain) favor the H-rich ferritins, with a significant anti-oxidant activity (Wagstaff et al. 1978; Harrison and Arosio 1996); since the $\mathrm{L}$ and $\mathrm{H}$ ferritin gene transcription is modulated by different stimuli (see below), the composition of the multimeric protein may also be affected by factors such as oxidative stress, inflammation and hypoxia. In contrast to the cytosolic ferritin, the mitochondrial ferritin is a 24-mer homopolymer: the mitochondrial subunit is encoded by a distinct, nuclear and intronless gene; its 
protein products has a $\mathrm{N}$-terminal targeting sequence that drives the protein to mitochondria, where it is processed to a mature peptide with a size similar to that of the $\mathrm{H}$ and $\mathrm{L}$ peptides (Drysdale et al.). Ferritins are found also in other cellular compartments (lysosomes and nucleus), in extracellular fluids and in the blood. Serum ferritin is predominantly made by L subunits (Cazzola et al. 1985; Santambrogio et al. 1987) and is a significant clinical parameter for the diagnosis and monitoring of iron overload or deficiency. Different reviews dealt with this topic (Wang et al. 2010; Ferraro et al. 2012) that will be not further considered in this manuscript.

\section{Iron flux in and out the ferritin cage.}

The 24 subunits come together in a three-dimensional structure that is designed for the dynamic storage of iron; extensive intra- and inter-subunits helix-helix interactions give rise to a very stable protein (it resists up to $80 \mathrm{C}^{\circ}, 6 \mathrm{M}$ guanidine and $\mathrm{pH} 3-10$ ) (Martsev et al. 1998) yet maintaining sufficient flexibility to allow the flux of iron and other small molecules in and out of its shell (Liu and Theil 2005). The protein actually shows eight narrow hydrophilic channels around the 3 -fold symmetry axes and six hydrophobic channels around the 4-fold axes, all with a diameter of about $0.4 \mathrm{~nm}$ (figure 1). Compelling in vitro evidence suggests that the iron entry route is represented by the hydrophilic channels (Chasteen 1998; Yang et al. 2000) whereas the hydrophobic ones seem to be involved in the diffusion of oxygen and hydrogen peroxide (Liu and Theil 2005). The transfer of iron inside the cavity has been extensively studied in vitro; in the accepted mechanism Fe(II) binds to ferritin via carboxylate side chains that line the 3 -fold axes pores and then moves to the ferroxidase center. Here two iron atoms bind to the catalytic site where oxidation occurs in the presence of $\mathrm{O}_{2}$ and with the generation of hydrogen peroxide. The latter is consumed for iron oxidation in neighboring ferroxidase centers (Zhao et al. 2003). This couples the storage activity to an anti-oxidant reaction that consumes the reagents of the Fenton reaction (figure 3C). The oxidized iron atoms move to the cavity, hydrolyze and form the mineral core (Bou-Abdallah et al. 2002). The iron core offers sites that facilitate iron oxidation, in competition with the ferroxidase center, allowing the direct oxidation and deposition of the metal on the mineral surface (Chasteen and Harrison 1999; Bou-Abdallah 2010). The structure of native and reconstituted iron cores has been studied by various physical and chemical approaches and different models have been proposed. Recent analysis performed with nanoanalysis techniques (Quintana and Gutiérrez 2010) indicate that ferritin cores have a polyphasic structure, with two or three crystalline phases (ferrihydrite, magnetite and hematite) co-existing inside the cavity (Cowley et al. 2000; Gálvez et al. 2008). Iron loading mechanisms inside the cells probably reflect those studied in vitro, even though higher level of complexity and regulation may be present; in particular the interaction and loading of ferritins with iron may be enhanced in vivo by iron chaperones such as the PCBPs that can interact with ferritin with nanomolar affinity and may deliver iron directly at the hydrophilic pores (Shi et al. 2008; Leidgens et al. 2013). This activity is not specific to ferritin since PCBP1 and PCBP2 also facilitate iron delivery to enzymes with mononuclear and dinuclear iron centers, deoxyhypusine hydroxylase and prolyl and asparagyl hydroxylases respectively (Nandal et al. 2011; Frey et al. 2014) and PCBP2 can mediate cytosolic iron distribution by interacting with the membrane transporters DMT1 and Ferroportin (Yanatori et al. 2014). Further studies are needed to understand the role of these ubiquitous RNA/DNA binding proteins in the maintenance of iron homeostasis.

The iron stored in the ferritin cavity is readily available to cellular demand. The mechanisms governing the exit of the metal from the protein deposit are not clear yet and the physiological 
relevance of the data obtained in vitro is still debated. The 3-fold channels seem to be the main route of both iron entry and exit from the protein shell (Wardeska et al. 1986), with the negatively charged amino acids paving their surface playing a fundamental role in determining the types of ions and molecules that can access inside the cage (Takahashi and Kuyucak 2003). In vitro, the removal of iron is efficient in the presence of reducing agents and chelators, even those larger than the diameter of the channel (Jones et al. 1978; Watt et al. 1988); this could be explained by a direct transfer of electrons from the exterior reductants to the inner mineral core through the $2 \mathrm{~nm}$ ferritin wall. In bacterial ferritin the transfer seems to be facilitated by the heme groups in proximity to the mineral core (Richards et al. 1996), but it was described also in animal ferritin heteropolymers with $\mathrm{H}$ and L subunits (Johnson et al. 1999). Also a significant flexibility of the channels has to be taken into account, thus considering that they may behaves similarly to the gated pores that regulate molecules diffusion through the cell membranes (Theil et al. 2008). Increasing temperature, physiological concentration of chaotropic reagents or site-directed mutagenesis of specific residues of tadpole M-ferritin (Leu-110, Arg-72 an d Asp-122) have been shown to dramatically increase the in vitro rate of ferritin iron release by altering the stability of the 3-fold channels. Furthermore, the screening of a combinatorial library brought to the identification of peptides capable of binding to ferritin, opening or closing the pores and thus modulating the rate of iron release (Liu et al. 2007). This finding led to the speculative proposal of regulatory molecules controlling the breathing of the gated pores in vivo. Of note, significant reduction in iron retention could be observed also when ferritins with a perturbed 4-fold channels structure were expressed in HeLa cells (Cozzi et al. 2006; Cozzi et al. 2010). Despite the detailed in vitro studies and the proposed models, the in vivo physiological relevance of direct iron release from ferritins is far from clear. In order to be mobilized iron must be reduced to soluble Fe(II) ions, but the physiological reducing machinery has not been identified, and, more important, if the mechanism is not tightly regulated it probably involves one-electron transfer process that is potentially toxic for the generation of free radicals. This means that ferritin iron under certain conditions may exert pro-oxidant activity. In fact this has been observed in some reports. The incubation of ferritin with $\mathrm{H}_{2} \mathrm{O}_{2}$ (Liu and $\mathrm{Hu}$ 2009), salsolinol (Kang 2009) or methylglyoxal and lysine (An and Kang 2013) caused oxidative DNA damage, and this was prevented by iron chelators. Furthermore the presence of mutant $\mathrm{L}$ ferritin with a perturbed $\mathrm{COOH}$-terminal structure as observed in neuroferritinopathy patients leads to excess LIP and ROS generation (see also below) (Levi and Finazzi 2014). It is thus possible that, in specific chemical or genetic conditions, iron release from ferritin may be toxic to cells and tissues and contribute to the pathology.

In vivo, the major way to mobilize iron from its cellular storage is via the degradation of the ferritin cage itself (Linder 2013), as shown in cells exposed to restriction of iron availability (Truty et al. 2001). The involvement of lysosomes in ferritin degradation and the concomitant iron release has been shown in different cell lines exposed to iron chelating agents (particularly deferoxamine (DFO) or overexpression of FtMt) (Kidane et al. 2006; Zhang et al. 2010), bacterial infection (Larson et al. 2004), and ferroportin activation (Asano et al. 2011). Lysosomal inhibitors, but not proteasomal inhibitors, could halt the degradation, induce ferritin accumulation in the organelles and block iron release. Very recently a quantitative proteomic study identified the Nuclear Receptor Coactivator 4 (NCOA4) as a cargo receptor mediating ferritin delivery to the autophagosome (Mancias et al. 2014), thus indicating a possible new level of regulation of cellular iron homeostasis. The intra-lysosomal degradation of ferritin has the advantage to shield the other 
cellular components by the potential toxicity of iron allowing a controlled release of the metal to the cytosol, where it increases LIP level (Asano et al. 2011) and induces ferritin synthesis (Garner et al. 1998). Nonetheless there are reports showing that ferritin, and particularly apo- and iron poorferritin, can be degraded also by the proteasome. Indeed, oxidized ferritin is a target of proteasome degradation (Rudeck et al. 2000) and lactacystin, a proteasome inhibitors, can increase ferritin stability in iron replete cells (Zhang et al. 2010). The overexpression of ferroportin in HEK293 cells in iron replete conditions induced ferritin loss (but apparently not iron release) via ubiquitination and proteasome degradation (De Domenico et al. 2006). Similar results were obtained exposing the same cells to deferasirox and deferiprone, chelating agents targeted to the cytosol, whereas DFO induced the lysosomal pathway (De Domenico et al. 2009). Interestingly, the expression of neuroferritinopathy-related L ferritin mutants in HeLa cells was associated with an increased proteasomal degradation of ferritin (Cozzi et al. 2006). Altogether both the lysosomal and the proteasomal pathways of degradation seem to be recruited to mobilize iron from ferritin, probably depending on the cell type and the cellular conditions.

\section{Regulation of ferritin expression}

The main functions of the cytosolic ferritins are the reversible storage of iron and the prevention of iron-mediated oxidative stress. This is supported by the stimuli and mechanisms involved in controlling their expression, mostly related to iron and stress, both at the transcriptional and the translational levels (Torti and Torti 2002; Theil 2007). Transcriptional mechanisms are involved in determining the tissue specific $\mathrm{H}$ to $\mathrm{L}$ ratio and are only modestly elicited by chronic iron supplementation (Cairo et al. 1985). However heme was shown to be a strong inducer in some cellular systems: it acts by removing Bach1 repressor and permitting the binding of the transcription factor Nrf2 (Hintze and Theil 2006; Hintze et al. 2007). Also oxidative stress induced a significant increase (up to 80 fold) in ferritin mRNA (Torti and Torti 2002; Hintze and Theil 2005). A combination of different repressor (Bach1 and ATF1) (Iwasaki et al. 2007; Hintze et al. 2007) and activators (Nrf2, JunD) (Iwasaki et al. 2006; MacKenzie et al. 2008) are involved in the recognition and binding of the Antioxidant Response Elements (ARE) in the promoter region of mouse ferritin $\mathrm{H}$ and $\mathrm{L}$ genes, modulating their expression in response to oxidative stimuli. Different signaling cascades may enroll such DNA binding factors; for instance, the activation of PI3-kinase was required for ferritin $\mathrm{H}$ induction by oxidative agents in Jurkat cells (Sakamoto et al. 2009); in the same cell type resveratrol, a molecule with antioxidant properties, induced ferritin $\mathrm{H}$ transcription via the recruitment of AMP-activated kinase (Iwasaki et al. 2013). The induction of ferritin for detoxification purposes has been observed also in other condition of cellular stress: genotoxic stimuli (doxorubicin and etoposide) were shown to increase ferritin $\mathrm{H}$ transcription through the activation of the Homeodomain Interacting Protein Kinase 2 (HIPK2) and consequent removal of the ATF1 repressor in MEF cells (Hailemariam et al. 2010); similarly inflammatory stimuli and particularly TNF- $\alpha$ and Interleukin- 1 and -6 , can induce ferritin expression, and particularly the $\mathrm{H}$ chain (Torti and Torti 2002). The increased capacity to sequester iron is an efficient protective mechanism against cellular stress, as shown by the block of the TNF- $\alpha / \mathrm{JNK}$ mediated apoptosis obtained through the NF-kb-dependent activation of ferritin transcription (Pham et al. 2004). Other pathways of regulation suggest the possible association of ferritin with alternative, cell specific functions (see below); adiponectin can increase ferritin expression in primary skeletal muscle cells by recruitment of NF-kb (Ikegami et al. 2009) while in neurons a 
transcription-dependent increase of ferritin $\mathrm{H}$ is observed upon the activation of $\mu$-opiod receptors (Sengupta et al. 2009). A strong post-transcriptional regulation of ferritin is superimposed to the transcriptional one to guarantee rapid adaptations to changes in iron levels and oxidative stress. This mechanism represents an elegant example of coordinated cytosolic regulation of gene expression (Hentze et al. 1989). It is based on the action of two Iron Responsive Proteins, IRP1 and IRP2. They can bind with high affinity to an hairpin structure, the Iron Responsive Element (IRE), located in the 5'-UTR of ferritin H and L mRNAs (Theil 2007). The binding is modulated by cellular iron and redox status: when iron levels are low, both IRP1 and IRP2 sit onto the IREs of H and L (figure 4) mRNAs, thus blocking their translation; when iron is available IRP2 is degraded by the proteasome (Guo et al. 1995), while IRP1 binds to a 4Fe-4S cluster and covert to the cytosolic aconitase enzyme (Rouault and Tong 2005). Under oxidative condition the iron sulfur cluster of aconitase can be destroyed, thus inducing the switch to IRP1 (Pantopoulos et al. 1997), while the oxidation of cysteines in IRP2 promotes its degradation (Zumbrennen et al. 2009). Under reducing condition there is no urgent need to sequester iron and ferritin synthesis can be repressed, while the opposite happens in the presence of an oxidative environment. No definitive explanation exist yet for the existence of two IRPs with different type of regulation, even though IRP2 seems to be the only functional IRE ligand at low oxygen tension (Hanson et al. 2003).

\section{Cytosolic ferritin, iron and ROS production: a delicate balance.}

The fundamental role of ferritin as a storage and antioxidant agent is documented by a significant amount of data generated both in vitro and in vivo and related to different pathophysiological conditions (Arosio and Levi 2010). The overexpression of ferritin H in HeLa (Cozzi et al. 2000) and erythroleukemia cells (Epsztejn et al. 1999) resulted in decreased iron and ROS generation, increased resistance to oxidative stress and prevention of TNF- $\alpha$ induced apoptosis (Cozzi et al. 2003). The overexpression of $\mathrm{H}$ mutants lacking the ferroxidase activity or of ferritin L did not induce the same phenotype, while the downregulation of ferritin $\mathrm{H}$ by specific siRNA had opposite effects. These results confirm the determinant role of ferritin $\mathrm{H}$ for the detoxification activity, and suggest that a correct balance in the expression of ferritin subunits may be similarly important. We may predict that abnormal low levels of ferritin $\mathrm{H}$ can be detrimental, as it occurs in the brain of mice with the deletion of a ferritin $\mathrm{H}$ allele that show perturbation of iron and redox balance (Thompson et al. 2003), but also an excess of ferritin $\mathrm{H}$ may perturb iron homeostasis and cause a pro-oxidant condition, in the long run. An interesting example of this was the finding that the overexpression of ferritin $\mathrm{H}$ in the substantia nigra of mice protected young mice from the noxious action of MPTP, but had opposite results in older mice (Kaur et al. 2003; Kaur et al. 2009). The balance can be altered in defects of FtL, as it occurred in a subject homozygous for enabling loss of function mutation of the FtL gene. The fibroblasts and reprogrammed neurons from the subject showed a reduced cellular iron availability associated with reduced catalase and SOD1 expression and with increased oxidative damage (Cozzi et al. 2013). So a correct balance of H and L subunits seems to be important for the proper dynamic equilibrium of cytosolic iron storage and availability. The in vitro data are confirmed and extended by analysis in vivo. The deletion of ferritin $\mathrm{H}$ in mice is embryonic lethal (Ferreira et al. 2000), while its conditional deletion in the adult mice led to a dramatic decrease in iron stores and a high sensitivity to iron excess and oxidative damage, both in the mice and the derived MEFs (Darshan et al. 2009). Mice with different FtH tissue-selective deletions were generated by mating animals with floxed FTH gene and transgenic mice with cre- 
recombinase under different promoters. The specific deletion of the gene in the kidney proximal tube was associated with decreased ferroportin levels and higher mortality upon induction of acute kidney injury (Zarjou et al. 2013). Increased LIP and ROS and mitochondrial depolarization were observed in lymphocytes form mice with Mx-Cre mediated conditional deletion (Vanoaica et al. 2014); the survival and maturation of B-cells exposed to B-cell activating factor was reduced and partially rescued by iron chelation with deferiprone. Interestingly, the deletion of the gene in the intestine was associated with increased iron body stores and related parameters (transferrin saturation, hepatic hepcidin mRNA level); nonetheless intestinal iron absorption was twofold higher than in wild type animals, thus suggesting a role for ferritin in the "mucosal block", the balance between iron retained in the cells and the ones to be transferred through basolateral membrane (Vanoaica et al. 2010). The storage and anti-oxidant action of cytosolic ferritin has been shown to exert a strong protective effect in different in vivo models of cellular/organ stress. The ischemia/reperfusion injury is associated to many pathological conditions and protection against it is an important issue in modern medicine. It has been shown that exposure of the organ to a minor ischemic stress (ischemic preconditioning, IPC) before the overt ischemia/reperfusion has beneficial effects, with reduction of infarct size and acceleration of the recovery of the heart (Yang et al. 2010). The strong induction of ferritin was found to have a major role in the IPC protection (Chevion et al. 2008). The induction was attributed to a rapid burst of free iron induced by a fast degradation of ferritin itself; this leads to apoferritin synthesis with consequent reduction of free iron and of the ROS production associated with the reperfusion process (Bulvik et al. 2012). Similar results have been obtained also in the retina (Obolensky et al. 2008) and in the hypothermic preconditioning of endothelial cells (Zieger and Gupta 2009). A protective effect from the prooxidant action of heme has been shown in a mouse model of sickle cell anemia, where the overexpression of $\mathrm{FtH}$, but not of $\mathrm{FtL}$ or of a mutated $\mathrm{FtH}$ without ferroxidase activity, significantly reduced the vascular stasis elicited by infusion of haemoglobin (Vercellotti et al. 2014). Data obtained both in mice and humans documented that iron sequestration by FtH can be crucial for the development of tolerance to malaria. The infection by Plasmodium was associated with the activation of the pro-apoptotic c-Jun N-terminal kinase (JNK), that, in turns, inhibited ferritin expression and promoted tissue iron overload and damage. When $\mathrm{FtH}$ (in mice) or ferritin (in humans) was over-expressed, it sequestered free iron and attenuated ROS production and JNK induction; this led to limitation of tissue damage, regardless of iron overload and pathogen burden (Gozzelino et al. 2012).

\section{Mitochondrial ferritin.}

Recently a mitochondrial ferritin (FtMt) has been identified (Levi et al. 2001). It is encoded by an intronless gene at human chromosome $5 \mathrm{q} 23.1$. It is synthesized as a precursor with a $\mathrm{NH}_{2}$-terminal stretch of charged amino acids that targets the peptide to the mitochondria; here a proteolytic processing generates the mature peptide, very similar to the cytosolic $\mathrm{H}$ chain, for sequence, structure and presence of a ferroxidase center (Langlois d'Estaintot et al. 2004; Levi and Arosio 2004). In fact the recombinant mature protein incorporates iron in vitro as efficiently as recombinant FtH (Bou-Abdallah et al. 2005). Contrary to the ubiquitous cytosolic ferritin, MtFt expression is limited to a few organs and cell types: in mice and humans the highest levels are found in testis, an particularly in spermatozoa, but mRNA and protein can be detected also in neurons of the brain and spinal cord, in the heart, kidney and pancreatic islet of Langherans 
(Santambrogio et al. 2007; Snyder et al. 2009; Wang et al. 2011). Since the mRNA lacks an IRE hairpin structure its expression is not regulated by iron at post-translational level and the protein is absent in iron storage organs, such as the liver and spleen. When overexpressed in cell lines, the protein causes a shift of cellular iron to mitochondria, with consequent iron deficiency in the cytosol (low ferritin and high TfR) and iron accumulation in the organelles (Corsi et al. 2002; Nie et al. 2005; Wu et al. 2013). This suggests that FtMt can cooperate with cytosolic ferritin in the maintenance of intracellular iron balance. It was also suggested that the main function of FtMt is the control of local iron availability of ROS production in mitochondria, particularly in cells with high metabolic rate. The expression of FtMt protected HeLa cells from different types of oxidative damage (Campanella et al. 2009) and reverted the perturbation of iron homeostasis induced by exposure to doxorubicin (Cocco et al. 2013). The expression of FtMt was also shown to rescue the phenotype associated with frataxin deficiency, in yeast and mammalian cells (Campanella et al. 2009) and partially also in fibroblasts form Friedrich Ataxia patients (Campanella et al. 2009), preventing ROS generation and mitochondrial iron loading, restoring the respiratory efficiency and preserving mitochondrial DNA integrity. When overexpressed in neuroblastoma SH-SY5Y cells, it protected the cells form the noxious activity of 6-OHDA (Shi et al. 2010) and also of A $\beta 25-35$ peptide (Wu et al. 2013); in both cases ROS production and apoptosis induced by the toxic stimuli were significantly attenuated. Supporting evidence for these antioxidant role come also from in vivo experiments. Mice lacking the gene are viable and have normal life span in normal condition (Bartnikas et al. 2010), but when exposed to doxorubicin they showed enhanced mortality with mitochondrial damage, fibril disorganization and signs of oxidative damage in the heart (Maccarinelli et al. 2014). Interestingly the down-regulation of FtMt expression in the hippocampus of rats obtained by injection of specific siRNA molecules was associated with increased apoptosis and the exposure of animal to A $\beta 25-35$ peptide aggravated the phenotype with more intense oxidative damage (Wu et al. 2013); whether this effects in the animals were linked to alteration of iron handling was not shown. Some aspects of the role played by FtMt and iron balance in mitochondria and cells remain poorly understood and expect further comprehension. For instance, FtMt and mitochondrial iron deposits are found at highest levels in the ringed sideroblasts of Sideroblastic Anemia (SA, OMIM 300751) (Cazzola et al. 2003). It was initially thought that FtMt was a protective response to mitochondrial iron loading, but it was found that the enhanced expression of FtMt preceded iron accumulation, already at very early stages of erythroid differentiation and before signs of iron deposition (Della Porta et al. 2006). The understanding of such phenotype requires a deeper description of the mechanisms regulating the expression of the protein, that are almost completely unraveled.

\section{Ferritin mutations in genetic disorders.}

The crucial role of ferritin in the maintenance of iron balance is also confirmed by the analysis of the pathogenesis of different human disorders associated with perturbation of iron homeostasis. The most paradigmatic example is Neuroferritinopathy (OMIM, 606159), an autosomal dominant neurodegenerative disorder due to mutations in the FtL gene and mainly characterized by extrapyramidal symptoms (McNeill and Chinnery 2012; Levi and Finazzi 2014). Magnetic resonance imaging reveals signs of cerebral iron accumulation, particularly in the basal ganglia (Crompton et al.), and the histopathology confirmed the iron accumulation together with the 
presence of ferritin aggregates, with a nuclear or cytosolic localization, in neurons and glial cells; serum ferritin is often decreased (McNeill and Chinnery 2012). Different type of sequence variations have been found in patients (figure 5), all of them, but one, are nucleotide insertions in exon 4 of the FtL gene and alter the C-terminus of the FtL protein. Mice expressing high level of a human FtL mutant (c.498-499dup) were described to recapitulate the human phenotype with motor impairment, shorter life span, iron accumulation and ferritin rich inclusion bodies in the brain and in different organs (Vidal et al. 2008). The in vivo (Vidal et al. 2008; Barbeito et al. 2009) and in vitro data (Cozzi et al. 2006; Baraibar et al. 2008) suggest that the mutant FtLs co-assemble with the endogenous ferritin and affect both iron loading and iron release. This would lead to a vicious cycle in which the augmented free iron pool would stimulate the synthesis of endogenous ferritin; the lack of a proper chelating capacity of the polymer would result in increased ROS generation, intensification in protein ubiquitination, proteasomal dysfunction and accumulation of ferritin aggregates (Levi and Finazzi 2014). The disorder is the most compelling evidence that perturbation of ferritin function and iron homeostasis may lead to neurodegeneration. No mutation in the coding sequence of $\mathrm{FtH}$ are known, indirectly confirming that the absence of such protein is not compatible with life. Sequence variations in the IRE at the 5'UTR of ferritin L are associated with the Hereditary Hyperferritinemia Catarct Syndrome (OMIM600886), with elevated serum ferritin levels and early appearance of bilateral cataract (Beaumont et al. 1995). Numerous type of mutations have been identified; they all reduce the affinity of the IRE for IRPs, thus resulting in a constitutive overexpression of the FtL protein. This seems to cause ferritin L precipitation in the lenses (Goralska et al. 2001; Kannengiesser et al. 2009), but no alterations of iron homeostasis, even though the FtL excess occurs in all tissues. Also FtL haploinsufficiency did not lead to any clinical manifestation or evident perturbation of iron homeostasis (Cremonesi et al. 2004) and one case with homozygous inactivation of FtL gene did not show evident problems in iron regulation but some neurological defects, such as idiopathic generalized seizures and atypical restless leg syndrome (Cozzi et al. 2013). These data strongly indicate that FtL does not have a central role in the regulation of iron homeostasis.

\section{Ferritin in brain disorders with altered iron homeostasis.}

Iron is an abundant metal in the brain, mostly localized in the Substantia Nigra (SN) and in the basal ganglia, with concentrations similar to those of the liver. The amount of the metal increases with aging (Bartzokis et al. 1999; Zecca et al. 2005), but this is not necessarily linked to pathological alteration or dysfunction of the brain; a parallel increase of ferritins is actually observed in normal aging (Connor et al. 1995) that should guarantee the safe storage and handling of the metal. Local siderosis has been linked to different neurodegenerative disorders, including Alzheimer's (AD) and Parkinson's disease (PD); however its clinical relevance and its role in the pathogenesis are largely unraveled; on one hand iron accumulation could be associated to excess labile iron that could play a causative or exacerbating role in disease development by increasing ROS generation, on the other hand its deposition may be simply an epiphenomenon of cell death due to other unrelated causes. A direct relationship between total iron (in the plasma) and labile iron pool (in the cells) is evident in experimental or clinical systemic iron overload, where the benefits obtained with a cell-permeant iron chelator confirm the pathological relevance of non-ferritin bound iron (Pennell et al. 2011). Even though the generating mechanisms of brain siderosis are different, the same setting may be found in it, as suggested by the promising results obtained by targeting chelatable iron with deferiprone in an experimental model of PD and in early-stage PD patients 
(Devos et al. 2014). Important aspects in this possible pathogenic mechanisms are not clear yet; in particular, what is the difference between iron accumulation in normal ageing and in neurodegenerative disorders with brain iron overload? Is it just a matter of amount of iron or other mechanisms controlling iron balance are involved; if the IRP-dependent system controlling the intracellular iron homeostasis is efficient in the first condition, is it no more competent in the latter? Being cytosolic ferritin an important factor in determining intracellular LIP, its analysis may provide insight into this aspects. Ferritin is the main iron storage molecule also in the brain; immunohistochemistry (IHC) analysis show that it is abundant in oligodendrocytes, with both $\mathrm{H}$ and L chains, it is present in glial cells, where the L chain is predominant, and in neurons, mostly as $\mathrm{H}$ chain (Connor et al. 1994). In the whole brain the $\mathrm{H}$ chain is more abundant than the $\mathrm{L}$ one and both increase with age, in parallel to iron. Since ferritin levels are mainly controlled by iron availability, its measurement by IHC or western blotting is usually considered as a marker of the metal distribution in the brain parenchyma, useful to confirm MRI data eventually indicating perturbation in brain iron density. For example, imaging and transcranial sonography studies indicated reduced concentration of iron in the SN of patients with early onset of the Restless Legs Syndrome, but normal iron in those with late onset (Schmidauer et al. 2005; Earley et al. 2006). The histological analysis of the same brain region in autopsies of the first group showed a reduction of ferritin (particularly of the $\mathrm{H}$ chain) in melanized neurons, that paralleled the hypointense signal of MRI (Connor et al. 2003). Interestingly such reduction was accompanied by an increase of FtMt (Snyder et al. 2009). In most conditions, ferritin behaves as a dynamic storage, adjusting its level and expression according to the local abundance of iron and controlling LIP level. Whether this fluctuations and adjustments are always perfectly fit to the need and balance of the neural cells is difficult to know. Alteration in this dynamic equilibrium could be dangerous, giving rise to excess of free iron or, alternatively, to excess iron sequestration. Such an "iron imbalance" in the brain could have different origins, but the switch of ferritin from the protective storage role to a prooxidant action has been observed in different in vitro and in vivo experimental settings (see above) and may be relevant in some pathological conditions. This is clearly suggested by the discovery that mutations in ferritin gene leads to Neuroferrintinopathy, a neurodegenerative disorder with brain iron accumulation. In particular, the study of in vitro and in vivo models of the disease have shown that the alteration of ferritin capacity to safely load and retain iron gives raise to excess free and redox-active iron, augmented oxidative damage, neuronal degeneration and death (Levi and Finazzi 2014). Whether similar processes may take place in other forms of sporadic neurodegenerative disorders is not clear yet, even though some indication are present in the literature. In AD iron is particularly increased in the parietal cortex, motor cortex, and hippocampus (Zecca et al. 2004). Most of it co-localize with the A $\beta$ plaques. IHC and transmission electron microscopy (TEM) analyses revealed that also ferritin intensively decorates the senile plaques and the surrounding glial cells (Lovell et al. 1998; Roberts et al. 2012). The overall increase in ferritin seems to exceed that of iron, at least in the hippocampus of AD patients, hence most iron should be ferritin-bound (Galazka-Friedman et al. 2004), thus in a safe state. Interestingly a quantitative analyses of isoferritins in the brain of controls and $\mathrm{AD}$ patients found region and disease specific alteration of the balance between $\mathrm{H}$ and $\mathrm{L}$ subunits, with the $\mathrm{L}$ subunit concentration being lower in the cortex and in the SN of AD brain (Connor et al. 1995); a proteomic analysis of AD hippocampi also found elevated H-chain levels (Sultana et al. 2007). As observed in different experimental systems, this imbalance could be associated with an abnormal iron management by ferritin itself. Possible support for this hypothesis came from the analysis of the composition of ferritin cores performed by 
analytical TEM (Quintana and Gutiérrez 2010): while ferrihydrite, with an hexagonal cell unit, was the major component of the mineral core in ferritin from non-pathological samples, mixed ferric and ferrous oxide, with a cubic cell unit, were found in ferritin from AD brains. Further work is required to support the speculative suggestion of differences in the biomineralization process catalyzed by ferritin in patients' brains and their role in the development and/or progression of the neurodegenerative process. PD is a neurodegenerative disorder characterized by the progressive death of neurons in the SN pars compacta, with accumulation of $\alpha$-synuclein, formation of Lewy bodies, intensive reactive gliosis and functional decay of the nigro-striatal circuitry (Zecca et al. 2004). The hypothesis of an increase of iron in the SN of patients is generally accepted and documented (Sofic et al. 1988; Dexter et al. 1989; Oakley et al. 2007), even though the difference between controls and PD samples appears to be affected by factors such as disease severity, gender or age of onset (Snyder and Connor 2009). Less clear are the modification of ferritin levels, with studies showing an increase (Sofic et al. 1988; Licker et al. 2014), a decrease (Dexter et al. 1990; Connor et al. 1995; Faucheux et al. 2002) or changes in the relative H/L ratio (Koziorowski et al. 2007), with consequent functional implication for iron handling. The loss of neurons (rich in $\mathrm{H}$ subunit), the reactive gliosis (microglial cells are rich in L ferritin) as well as technical aspects such as the type of antibodies applied for IHC may be important confounding factor in this analysis (Snyder and Connor 2009). Albeit adequate in total amount, ferritin may be defective in function, as suggested by the increased labile iron found in the SN of PD patients by atomic absorption (Wypijewska et al. 2010) and by the significant asymmetry of ferritin Moessabauer spectra in the same brain region from PD patients (Galazka-Friedman et al. 2004). When confirmed, this would suggest a possible loss of function of ferritin in the $\mathrm{SN}$ of patients. Perturbation of iron balance in the brain is also documented in prion diseases, a group of neurodegenerative disorders affecting humans (Crutzfeld Jacob disease), and animals (scrapie in sheep and goats, and chronic wasting disease in deer and elks) (Prusiner 1998). The main event in the pathogenesis of these disorders is the conformational change of the wild type prion protein (PrPC) to a pathological, $b$-sheet enriched form (PrPsc) (Prusiner 2013). The noxious activity of PrPsc is not defined yet. Interestingly mice lacking the gene showed signs of systemic iron deficiency (Singh et al. 2009b) and a progressive decrease of the metal is described in brains from affected patients or animals, despite an increase in total iron load (Singh et al. 2009a) together with loss of function of PrPC. There is evidence that PrPc could have ferroxidase activity and its absence could reduce iron uptake in diseased brain (Singh et al. 2013), but an important role could be attributed to the formation of aggregates between the PrPsc and iron-rich ferritin (Singh et al. 2012). The ferritin isolated form affected brains is insoluble and retains iron even when exposed to harsh denaturing conditions. These aggregates can exert a pro-oxidant activity and favor further accumulation of PrPsc and, in the long run, may lead to an iron-deficient phenotype with upregulation of TfR expression (Singh et al. 2014). Altogether these observation suggest that different factors (mutations, altered subunits ratio, interaction with other protein/molecules) may affect the ferritin capacity to properly modulate the dynamic sequestration and release of iron and induce a switch towards a pro-oxidant activity of the protein, possibly contributing to the development and/or progression of some neurodegenerative processes (figure 6). A possible involvement of ferritin in pathomechanisms of neurodegeneration may be also linked to novel non-iron-related functions (see below). Interesting examples are the binding between FtH and CXCR4 (Li et al. 2006) and FtL and Pen2 (Li et al. 2013). In the first case the interaction results in a negative modulation of the CXCL12/CXCR4 pathway, which is known to regulate neuronal migration, differentiation and survival. An (iron-dependent) increase in cytosolic 
ferritin could impinge on this signaling cascade and induce or accelerate the neural death. The interaction of FtL with Pen-2 seems to affect the $\gamma$-secretase activity and thus the processing of the Amyloid Precursor Protein (APP), resulting in an increased production of beta amyloid (A $\beta$ ), the main component of senile plaques and central pathological factor in AD. A direct relationship between iron level and $A \beta$ production has been recently observed also in a transgenic mouse model of $\mathrm{AD}$, together with perturbation of the glutamatergic neurotransmission (Becerril-Ortega et al. 2014). If one considers that iron levels regulates APP expression through an IRE in its mRNA (Rogers et al. 2002) and that APP itself may participate in the ferroportin-dependent iron efflux from the cells acting as a ferroxidase (Duce et al. 2010), it is then possible that the capacity of ferritin to control iron homeostasis in neural cells may be central in the pathogenesis of AD.

\section{Mammalian cytosolic ferritin, not only iron.}

Recent data suggest possible binding partners for the cytosolic ferritin, not necessarily linked to its role in iron homeostasis and indicating alternative functions. Robust data suggest involvements in signal transduction pathways. A functional interaction with granulocyte colony-stimulating factor (G-CSF) was documented both in COS-7 cells overexpressing G-CSF receptor and FtH and in mouse bone-marrow hematopoietc cells (Yuan et al. 2004). The interaction involved the $\mathrm{COOH}-$ terminus of the intracellular domain of G-CSF receptor. The treatment of the cells with G-CSF induced $\mathrm{FtH}$ dissociation after $30 \mathrm{~min}$, accompanied by an increase of intracellular LIP and ROS formation and Stat3 phosphorylation, thus suggesting the existence of a G-CSF-FHC-LIP-ROS pathway in hematopoietic cells. It has been shown that $\mathrm{FtH}$ acts as a negative regulator of the chemokine receptor CXCR4 via direct interaction with its intracellular domain (Li et al. 2006). Stimulation of CXCR4 by its ligand CXCL12 induces FtH phosphorilation at serine 178 and subsequent translocation to the nucleus. The discovery that opioids induce new synthesis of FtH can explain the heterologous desensitization observed between $\mu$-opioid receptors (MOR) and CXCR4 in neurons (Sengupta et al. 2009), a possible mechanism underlining the neurological dysfunction and cerebral damage determined by opiates. This activity is independent of iron binding since it is maintained by a ferroxidase deficient FtH (Pitcher et al. 2014). Since CXCR4 is also a coreceptor for HIV through gp120 and TAT proteins, it is possible that ferritin $\mathrm{H}$ induction represents the crossroad at which the signaling cascade of opiates and HIV meet to generate the deleterious cerebral effects often observed in HIV-positive opiate-abusers (figure 7). Indeed, drug abusers and HIV patients with neurological symptoms had increased levels of FtH (Pitcher et al.). Altogether the FtH-dependent deregulation of CXCL12/CXCR4 pathway seems to contribute to the development of cognitive dysfunction in neuroAIDS (Pitcher et al. 2014). Since the CXCL12/CXCR4 signaling cascade has important roles in different cellular types and functions (Cojoc et al. 2013), it could be of interest to verify the relevance of this data in cells other than neurons. In rat liver ferritin $\mathrm{H}$ and $\mathrm{L}$ interact with apolipoprotein B (ApoB), block its secretion and enhance its intracellular degradation (Rashid et al. 2002; Hevi and Chuck 2003). This action seemed to be independent from the iron binding capacity (Hevi and Chuck 2003) and may be mediated by hemin. This molecular interaction could be relevant in the regulation of lipid transport and storage in the liver and potentially explain the steatosis associated with HCV infection. A recent study showed that the viral infection upregulated $\mathrm{FtH}$ expression at a transcriptional level, independent of iron or oxidative stress, and inhibited the secretion of ApoB-containing lipoprotein particles. This could be rescued by FtH 
downregulation with specific siRNA. Interestingly, the reduction in FtH content was also associated with a less robust viral infection, thus indicating that FtH may be a host factor required for HCV infection (Mancone et al. 2012). On the basis of the possible role of iron in the development of neurodegenerative processes, it is of particular interest a recent report showing that FtL can interact with Pen-2, a subunit of the multiprotein complex associated with the $\gamma$-secretase activity, involved in the processing of the amyloid precursor protein ( $\mathrm{Li}$ et al. 2013). The interaction has been found by the yeast two hybrid system and co-immunoprecipitation of the two proteins in cells overexpressing them. FtL overexpression or its induction by iron resulted in Pen-2 stabilization and increased betaamyloid production due to stimulation of the $\gamma$-secretase activity. Opposite results were obtained by turning down FtL expression by specific siRNA. Further studies are needed to confirm the physiological relevance of the data. A peptide corresponding to amino acids 19 to 125 of the human $\mathrm{FtH}$ has been shown to interact with surviving, an anti-apoptotic protein strongly expressed in different types of cancer cells (Weiss et al. 2012). The peptide, expressed as a fusion protein with a variant of the human thioredoxin protein, was able to target the anti-apoptotic function of survivin and cause tumor cell death. The full length FtH did not show the same binding activity in the yeast two hybrid system, so it seems not probable that this can be a physiological interaction.

\section{Conclusions}

The ferritin molecule has been known for almost 80 years but new interesting aspects related both to iron homeostasis and other novel possible functions continue to emerge from its study. The strong relationship between iron and ROS generation puts ferritin in a cardinal position for the control of oxidative damage in the cells. The possibility that perturbation of the ferritin storage and antioxidant function could play a fundamental role in pathological processes associated with increased oxidative stress is of extreme interest, but, with the exception of the Neuroferritinopathy condition, it awaits for further experimental consolidation and analysis of the molecular mechanism involved in it; in this regard, and particularly for neurodegenerative processes, also the relationship between mitochondrial and cytosolic ferritin should be further explored. Cytosolic ferritin has been recently shown to interact with different protein partners and possibly to the participate to some specific, non-iron-related activities. In most cases the interaction has been attributed to a single ferritin chain, but in depth analyses of the interaction with the ferritin 24-mer is still lacking ad required to confirm the physiological relevance of the data. With this premises, we expect that the ferritin field will be of great interest for many years yet.

Figures 2 and 4 have been adapted and/or reprinted from Biochimica et Biophysica Acta, 1800 (2010) , F. Bou-Abdallah, The iron redox and hydrolysis chemistry of the ferritins, with permission from Elsevier.

\section{Acknowledgements}

The financial support of Telethon-Italia (Grants no. GGP10099 to PA and GGP11088 to DF) is gratefully acknowledged. 


\section{Bibliography}

An SH, Kang JH (2013) Oxidative damage of DNA induced by the reaction of methylglyoxal with lysine in the presence of ferritin. BMB Rep 46:225-9.

Andrews SC (2010) The Ferritin-like superfamily: Evolution of the biological iron storeman from a rubrerythrin-like ancestor. Biochim Biophys Acta 1800:691-705. doi:

10.1016/j.bbagen.2010.05.010

Arosio P, Levi S (2010) Cytosolic and mitochondrial ferritins in the regulation of cellular iron homeostasis and oxidative damage. Biochim Biophys Acta 1800:783-92. doi:

10.1016/j.bbagen.2010.02.005

Asano T, Komatsu M, Yamaguchi-Iwai Y, et al. (2011) Distinct mechanisms of ferritin delivery to lysosomes in iron-depleted and iron-replete cells. Mol Cell Biol 31:2040-52. doi: 10.1128/MCB.01437-10

Baraibar MA, Barbeito AG, Muhoberac BB, Vidal R (2008) Iron-mediated aggregation and a localized structural change characterize ferritin from a mutant light chain polypeptide that causes neurodegeneration. J Biol Chem 283:31679-89. doi: 10.1074/jbc.M805532200

Barbeito AG, Garringer HJ, Baraibar MA, et al. (2009) Abnormal iron metabolism and oxidative stress in mice expressing a mutant form of the ferritin light polypeptide gene. J Neurochem 109:1067-78. doi: 10.1111/j.1471-4159.2009.06028.x

Bartnikas TB, Campagna DR, Antiochos B, et al. (2010) Characterization of mitochondrial ferritindeficient mice. Am J Hematol 85:958-60. doi: 10.1002/ajh.21872

Bartzokis G, Cummings JL, Markham CH, et al. (1999) MRI evaluation of brain iron in earlier- and later-onset Parkinson's disease and normal subjects. Magn Reson Imaging 17:213-22.

Beaumont C, Leneuve P, Devaux I, et al. (1995) Mutation in the iron responsive element of the L ferritin mRNA in a family with dominant hyperferritinaemia and cataract. Nat Genet 11:444-6. doi: $10.1038 /$ ng $1295-444$

Becerril-Ortega J, Bordji K, Fréret T, et al. (2014) Iron overload accelerates neuronal amyloid- $\beta$ production and cognitive impairment in transgenic mice model of Alzheimer's disease. Neurobiol Aging 35:2288-301. doi: 10.1016/j.neurobiolaging.2014.04.019

Bou-Abdallah F (2010) The iron redox and hydrolysis chemistry of the ferritins. Biochim Biophys Acta 1800:719-31. doi: 10.1016/j.bbagen.2010.03.021

Bou-Abdallah F, Papaefthymiou GC, Scheswohl DM, et al. (2002) mu-1,2-Peroxobridged diiron(III) dimer formation in human H-chain ferritin. Biochem J 364:57-63.

Bou-Abdallah F, Santambrogio P, Levi S, et al. (2005) Unique iron binding and oxidation properties of human mitochondrial ferritin: a comparative analysis with Human H-chain ferritin. J Mol Biol 347:543-54. doi: 10.1016/j.jmb.2005.01.007 
Bulvik BE, Berenshtein E, Meyron-Holtz EG, et al. (2012) Cardiac protection by preconditioning is generated via an iron-signal created by proteasomal degradation of iron proteins. PLoS One 7:e48947. doi: 10.1371/journal.pone.0048947

Cairo G, Bardella L, Schiaffonati L, et al. (1985) Multiple mechanisms of iron-induced ferritin synthesis in HeLa cells. Biochem Biophys Res Commun 133:314-21.

Campanella A, Rovelli E, Santambrogio P, et al. (2009) Mitochondrial ferritin limits oxidative damage regulating mitochondrial iron availability: hypothesis for a protective role in Friedreich ataxia. Hum Mol Genet 18:1-11. doi: 10.1093/hmg/ddn308

Cazzola M, Arosio P, Bellotti V, et al. (1985) Immunological reactivity of serum ferritin in patients with malignancy. Tumori 71:547-54.

Cazzola M, Invernizzi R, Bergamaschi G, et al. (2003) Mitochondrial ferritin expression in erythroid cells from patients with sideroblastic anemia. Blood 101:1996-2000. doi: 10.1182/blood-2002-07-2006

Chasteen ND (1998) Ferritin. Uptake, storage, and release of iron. Met Ions Biol Syst 35:479-514.

Chasteen ND, Harrison PM (1999) Mineralization in ferritin: an efficient means of iron storage. J Struct Biol 126:182-94. doi: 10.1006/jsbi.1999.4118

Chevion M, Leibowitz S, Aye NN, et al. (2008) Heart protection by ischemic preconditioning: a novel pathway initiated by iron and mediated by ferritin. J Mol Cell Cardiol 45:839-45. doi: 10.1016/j.yjmcc.2008.08.011

Cocco E, Porrini V, Derosas M, et al. (2013) Protective effect of mitochondrial ferritin on cytosolic iron dysregulation induced by doxorubicin in HeLa cells. Mol Biol Rep 40:6757-64. doi: $10.1007 / \mathrm{s} 11033-013-2792-\mathrm{z}$

Cojoc M, Peitzsch C, Trautmann F, et al. (2013) Emerging targets in cancer management: role of the CXCL12/CXCR4 axis. Onco Targets Ther 6:1347-61. doi: 10.2147/OTT.S36109

Connor JR, Boeshore KL, Benkovic SA, Menzies SL (1994) Isoforms of ferritin have a specific cellular distribution in the brain. J Neurosci Res 37:461-5. doi: 10.1002/jnr.490370405

Connor JR, Boyer PJ, Menzies SL, et al. (2003) Neuropathological examination suggests impaired brain iron acquisition in restless legs syndrome. Neurology 61:304-9.

Connor JR, Snyder BS, Arosio P, et al. (1995) A quantitative analysis of isoferritins in select regions of aged, parkinsonian, and Alzheimer's diseased brains. J Neurochem 65:717-24.

Corsi B, Cozzi A, Arosio P, et al. (2002) Human mitochondrial ferritin expressed in HeLa cells incorporates iron and affects cellular iron metabolism. J Biol Chem 277:22430-7. doi: 10.1074/jbc.M105372200

Cowley JM, Janney DE, Gerkin RC, Buseck PR (2000) The structure of ferritin cores determined by electron nanodiffraction. J Struct Biol 131:210-6. doi: 10.1006/jsbi.2000.4292 
Cozzi A, Corsi B, Levi S, et al. (2000) Overexpression of wild type and mutated human ferritin Hchain in HeLa cells: in vivo role of ferritin ferroxidase activity. J Biol Chem 275:25122-9. doi: 10.1074/jbc.M003797200

Cozzi A, Levi S, Corsi B, et al. (2003) Role of iron and ferritin in TNFalpha-induced apoptosis in HeLa cells. FEBS Lett 537:187-92.

Cozzi A, Rovelli E, Frizzale G, et al. (2010) Oxidative stress and cell death in cells expressing Lferritin variants causing neuroferritinopathy. Neurobiol Dis 37:77-85. doi: 10.1016/j.nbd.2009.09.009

Cozzi A, Santambrogio P, Corsi B, et al. (2006) Characterization of the 1-ferritin variant 460InsA responsible of a hereditary ferritinopathy disorder. Neurobiol Dis 23:644-52. doi: 10.1016/j.nbd.2006.05.004

Cozzi A, Santambrogio P, Privitera D, et al. (2013) Human L-ferritin deficiency is characterized by idiopathic generalized seizures and atypical restless leg syndrome. J Exp Med 210:1779-91. doi: $10.1084 /$ jem.20130315

Cremonesi L, Cozzi A, Girelli D, et al. (2004) Case report: a subject with a mutation in the ATG start codon of L-ferritin has no haematological or neurological symptoms. J Med Genet 41:e81.

Crompton DE, Chinnery PF, Fey C, et al. Neuroferritinopathy: a window on the role of iron in neurodegeneration. Blood Cells Mol Dis 29:522-31.

Darshan D, Vanoaica L, Richman L, et al. (2009) Conditional deletion of ferritin H in mice induces loss of iron storage and liver damage. Hepatology 50:852-60. doi: 10.1002/hep.23058

De Domenico I, Vaughn MB, Li L, et al. (2006) Ferroportin-mediated mobilization of ferritin iron precedes ferritin degradation by the proteasome. EMBO J 25:5396-404. doi: 10.1038/sj.emboj.7601409

De Domenico I, Ward DM, Kaplan J (2009) Specific iron chelators determine the route of ferritin degradation. Blood 114:4546-51. doi: 10.1182/blood-2009-05-224188

Della Porta MG, Malcovati L, Invernizzi R, et al. (2006) Flow cytometry evaluation of erythroid dysplasia in patients with myelodysplastic syndrome. Leukemia 20:549-55. doi: 10.1038/sj.leu.2404142

Devos D, Moreau C, Devedjian JC, et al. (2014) Targeting chelatable iron as a therapeutic modality in Parkinson's disease. Antioxid Redox Signal 21:195-210. doi: 10.1089/ars.2013.5593

Dexter DT, Carayon A, Vidailhet M, et al. (1990) Decreased ferritin levels in brain in Parkinson's disease. J Neurochem 55:16-20.

Dexter DT, Wells FR, Lees AJ, et al. (1989) Increased nigral iron content and alterations in other metal ions occurring in brain in Parkinson's disease. J Neurochem 52:1830-6.

Drysdale J, Arosio P, Invernizzi R, et al. Mitochondrial ferritin: a new player in iron metabolism. Blood Cells Mol Dis 29:376-83. 
Drysdale JW, Adelman TG, Arosio P, et al. (1977) Human isoferritins in normal and disease states. Semin Hematol 14:71-88.

Duce JA, Tsatsanis A, Cater MA, et al. (2010) Iron-export ferroxidase activity of $\beta$-amyloid precursor protein is inhibited by zinc in Alzheimer's disease. Cell 142:857-67. doi: 10.1016/j.cell.2010.08.014

Earley CJ, B Barker P, Horská A, Allen RP (2006) MRI-determined regional brain iron concentrations in early- and late-onset restless legs syndrome. Sleep Med 7:458-61. doi: 10.1016/j.sleep.2005.11.009

Epsztejn S, Glickstein H, Picard V, et al. (1999) H-ferritin subunit overexpression in erythroid cells reduces the oxidative stress response and induces multidrug resistance properties. Blood 94:3593-603.

Faucheux BA, Martin M-E, Beaumont C, et al. (2002) Lack of up-regulation of ferritin is associated with sustained iron regulatory protein-1 binding activity in the substantia nigra of patients with Parkinson's disease. J Neurochem 83:320-30.

Ferraro S, Mozzi R, Panteghini M (2012) Revaluating serum ferritin as a marker of body iron stores in the traceability era. Clin Chem Lab Med 50:1911-6. doi: 10.1515/cclm-2012-0129

Ferreira C, Bucchini D, Martin ME, et al. (2000) Early embryonic lethality of H ferritin gene deletion in mice. J Biol Chem 275:3021-4.

Frey AG, Nandal A, Park JH, et al. (2014) Iron chaperones PCBP1 and PCBP2 mediate the metallation of the dinuclear iron enzyme deoxyhypusine hydroxylase. Proc Natl Acad Sci U S A 111:8031-6. doi: 10.1073/pnas.1402732111

Galazka-Friedman J, Bauminger ER, Koziorowski D, Friedman A (2004) Mössbauer spectroscopy and ELISA studies reveal differences between Parkinson's disease and control substantia nigra. Biochim Biophys Acta 1688:130-6. doi: 10.1016/j.bbadis.2003.11.005

Gálvez N, Fernández B, Sánchez P, et al. (2008) Comparative structural and chemical studies of ferritin cores with gradual removal of their iron contents. J Am Chem Soc 130:8062-8. doi: $10.1021 / \mathrm{ja} 800492 \mathrm{z}$

Garner B, Roberg K, Brunk UT (1998) Endogenous ferritin protects cells with iron-laden lysosomes against oxidative stress. Free Radic Res 29:103-14.

Goralska M, Holley BL, McGahan MC (2001) Overexpression of H- and L-ferritin subunits in lens epithelial cells: Fe metabolism and cellular response to UVB irradiation. Invest Ophthalmol Vis Sci 42:1721-7.

Gozzelino R, Andrade BB, Larsen R, et al. (2012) Metabolic adaptation to tissue iron overload confers tolerance to malaria. Cell Host Microbe 12:693-704. doi: 10.1016/j.chom.2012.10.011

Guo B, Phillips JD, Yu Y, Leibold EA (1995) Iron regulates the intracellular degradation of iron regulatory protein 2 by the proteasome. J Biol Chem 270:21645-51. 
Hailemariam K, Iwasaki K, Huang B-W, et al. (2010) Transcriptional regulation of ferritin and antioxidant genes by HIPK2 under genotoxic stress. J Cell Sci 123:3863-71. doi: $10.1242 /$ jcs.073627

Hanson ES, Rawlins ML, Leibold EA (2003) Oxygen and iron regulation of iron regulatory protein 2. J Biol Chem 278:40337-42. doi: 10.1074/jbc.M302798200

Harrison PM, Arosio P (1996) The ferritins: molecular properties, iron storage function and cellular regulation. Biochim Biophys Acta 1275:161-203.

Hentze MW, Rouault TA, Harford JB, Klausner RD (1989) Oxidation-reduction and the molecular mechanism of a regulatory RNA-protein interaction. Science 244:357-9.

Hevi S, Chuck SL (2003) Ferritins can regulate the secretion of apolipoprotein B. J Biol Chem 278:31924-9. doi: 10.1074/jbc.M303081200

Hintze KJ, Katoh Y, Igarashi K, Theil EC (2007) Bach1 repression of ferritin and thioredoxin reductase 1 is heme-sensitive in cells and in vitro and coordinates expression with heme oxygenase1, beta-globin, and NADP(H) quinone (oxido) reductase1. J Biol Chem 282:3436571. doi: 10.1074/jbc.M700254200

Hintze KJ, Theil EC (2006) Cellular regulation and molecular interactions of the ferritins. Cell Mol Life Sci 63:591-600. doi: 10.1007/s00018-005-5285-y

Hintze KJ, Theil EC (2005) DNA and mRNA elements with complementary responses to hemin, antioxidant inducers, and iron control ferritin-L expression. Proc Natl Acad Sci U S A 102:15048-52. doi: 10.1073/pnas.0505148102

Ikegami Y, Inukai K, Imai K, et al. (2009) Adiponectin upregulates ferritin heavy chain in skeletal muscle cells. Diabetes 58:61-70. doi: 10.2337/db07-0690

Iwasaki K, Hailemariam K, Tsuji Y (2007) PIAS3 interacts with ATF1 and regulates the human ferritin $\mathrm{H}$ gene through an antioxidant-responsive element. J Biol Chem 282:22335-43. doi: 10.1074/jbc.M701477200

Iwasaki K, Mackenzie EL, Hailemariam K, et al. (2006) Hemin-mediated regulation of an antioxidant-responsive element of the human ferritin $\mathrm{H}$ gene and role of Ref-1 during erythroid differentiation of K562 cells. Mol Cell Biol 26:2845-56. doi: 10.1128/MCB.26.7.28452856.2006

Iwasaki K, Ray PD, Huang B-W, et al. (2013) Role of AMP-Activated Protein Kinase in Ferritin H Gene Expression by Resveratrol in Human T Cells. Biochemistry 52:5075-5083. doi: $10.1021 /$ bi400399f

Johnson JL, Norcross DC, Arosio P, et al. (1999) Redox reactivity of animal apoferritins and apoheteropolymers assembled from recombinant heavy and light human chain ferritins. Biochemistry 38:4089-96. doi: 10.1021/bi982690d

Jones T, Spencer R, Walsh C (1978) Mechanism and kinetics of iron release from ferritin by dihydroflavins and dihydroflavin analogues. Biochemistry 17:4011-7. 
Kang JH (2009) Ferritin enhances salsolinol-mediated DNA strand breakage: protection by carnosine and related compounds. Toxicol Lett 188:20-5. doi: 10.1016/j.toxlet.2009.02.011

Kannengiesser C, Jouanolle A-M, Hetet G, et al. (2009) A new missense mutation in the L ferritin coding sequence associated with elevated levels of glycosylated ferritin in serum and absence of iron overload. Haematologica 94:335-9. doi: 10.3324/haematol.2008.000125

Kaur D, Rajagopalan S, Andersen JK (2009) Chronic expression of H-ferritin in dopaminergic midbrain neurons results in an age-related expansion of the labile iron pool and subsequent neurodegeneration: implications for Parkinson's disease. Brain Res 1297:17-22. doi: 10.1016/j.brainres.2009.08.043

Kaur D, Yantiri F, Rajagopalan S, et al. (2003) Genetic or pharmacological iron chelation prevents MPTP-induced neurotoxicity in vivo: a novel therapy for Parkinson's disease. Neuron 37:899909.

Kidane TZ, Sauble E, Linder MC (2006) Release of iron from ferritin requires lysosomal activity. Am J Physiol Cell Physiol 291:C445-55. doi: 10.1152/ajpcell.00505.2005

Koziorowski D, Friedman A, Arosio P, et al. (2007) ELISA reveals a difference in the structure of substantia nigra ferritin in Parkinson's disease and incidental Lewy body compared to control. Parkinsonism Relat Disord 13:214-8. doi: 10.1016/j.parkreldis.2006.10.002

Langlois d'Estaintot B, Santambrogio P, Granier T, et al. (2004) Crystal structure and biochemical properties of the human mitochondrial ferritin and its mutant Ser144Ala. J Mol Biol 340:27793. doi: 10.1016/j.jmb.2004.04.036

Larson JA, Howie HL, So M (2004) Neisseria meningitidis accelerates ferritin degradation in host epithelial cells to yield an essential iron source. Mol Microbiol 53:807-20. doi: 10.1111/j.1365-2958.2004.04169.x

Leidgens S, Bullough KZ, Shi H, et al. (2013) Each member of the poly-r(C)-binding protein 1 (PCBP) family exhibits iron chaperone activity toward ferritin. J Biol Chem 288:17791-802. doi: 10.1074/jbc.M113.460253

Levi S, Arosio P (2004) Mitochondrial ferritin. Int J Biochem Cell Biol 36:1887-9. doi: 10.1016/j.biocel.2003.10.020

Levi S, Corsi B, Bosisio M, et al. (2001) A human mitochondrial ferritin encoded by an intronless gene. J Biol Chem 276:24437-40. doi: 10.1074/jbc.C100141200

Levi S, Finazzi D (2014) Neurodegeneration with brain iron accumulation: update on pathogenic mechanisms. Front Pharmacol 5:99. doi: 10.3389/fphar.2014.00099

Li R, Luo C, Mines M, et al. (2006) Chemokine CXCL12 induces binding of ferritin heavy chain to the chemokine receptor CXCR4, alters CXCR4 signaling, and induces phosphorylation and nuclear translocation of ferritin heavy chain. J Biol Chem 281:37616-27. doi: 10.1074/jbc.M607266200

Li X, Liu Y, Zheng Q, et al. (2013) Ferritin light chain interacts with PEN-2 and affects $\gamma$-secretase activity. Neurosci Lett 548:90-4. doi: 10.1016/j.neulet.2013.05.018 
Licker V, Turck N, Kövari E, et al. (2014) Proteomic analysis of human substantia nigra identifies novel candidates involved in Parkinson's disease pathogenesis. Proteomics 14:784-94. doi: 10.1002/pmic.201300342

Linder MC (2013) Mobilization of stored iron in mammals: a review. Nutrients 5:4022-50. doi: $10.3390 /$ nu5104022

Liu X, Theil EC (2005) Ferritins: dynamic management of biological iron and oxygen chemistry. Acc Chem Res 38:167-75. doi: 10.1021/ar0302336

Liu XS, Patterson LD, Miller MJ, Theil EC (2007) Peptides selected for the protein nanocage pores change the rate of iron recovery from the ferritin mineral. J Biol Chem 282:31821-5. doi: 10.1074/jbc.C700153200

Liu Y, Hu N (2009) Electrochemical detection of natural DNA damage induced by ferritin/ascorbic acid/H2O2 system and amplification of DNA damage by endonuclease Fpg. Biosens Bioelectron 25:185-90. doi: 10.1016/j.bios.2009.06.035

Lovell MA, Robertson JD, Teesdale WJ, et al. (1998) Copper, iron and zinc in Alzheimer's disease senile plaques. J Neurol Sci 158:47-52.

Maccarinelli F, Gammella E, Asperti M, et al. (2014) Mice lacking mitochondrial ferritin are more sensitive to doxorubicin-mediated cardiotoxicity. J Mol Med (Berl). doi: 10.1007/s00109-0141147-0

MacKenzie EL, Ray PD, Tsuji Y (2008) Role and regulation of ferritin H in rotenone-mediated mitochondrial oxidative stress. Free Radic Biol Med 44:1762-71. doi:

10.1016/j.freeradbiomed.2008.01.031

Mancias JD, Wang X, Gygi SP, et al. (2014) Quantitative proteomics identifies NCOA4 as the cargo receptor mediating ferritinophagy. Nature 509:105-9. doi: 10.1038/nature13148

Mancone C, Montaldo C, Santangelo L, et al. (2012) Ferritin heavy chain is the host factor responsible for $\mathrm{HCV}$-induced inhibition of apoB-100 production and is required for efficient viral infection. J Proteome Res 11:2786-97. doi: 10.1021/pr201128s

Martsev SP, Vlasov AP, Arosio P (1998) Distinct stability of recombinant L and H subunits of human ferritin: calorimetric and ANS binding studies. Protein Eng 11:377-81.

McNeill A, Chinnery PF (2012) Neuroferritinopathy: update on clinical features and pathogenesis. Curr Drug Targets 13:1200-3.

Nandal A, Ruiz JC, Subramanian P, et al. (2011) Activation of the HIF prolyl hydroxylase by the iron chaperones PCBP1 and PCBP2. Cell Metab 14:647-57. doi: 10.1016/j.cmet.2011.08.015

Nie G, Sheftel AD, Kim SF, Ponka P (2005) Overexpression of mitochondrial ferritin causes cytosolic iron depletion and changes cellular iron homeostasis. Blood 105:2161-7. doi: 10.1182/blood-2004-07-2722 
Oakley AE, Collingwood JF, Dobson J, et al. (2007) Individual dopaminergic neurons show raised iron levels in Parkinson disease. Neurology 68:1820-5. doi:

10.1212/01.wnl.0000262033.01945.9a

Obolensky A, Berenshtein E, Konijn AM, et al. (2008) Ischemic preconditioning of the rat retina: protective role of ferritin. Free Radic Biol Med 44:1286-94. doi:

10.1016/j.freeradbiomed.2007.10.060

Pantopoulos K, Mueller S, Atzberger A, et al. (1997) Differences in the regulation of iron regulatory protein-1 (IRP-1) by extra- and intracellular oxidative stress. J Biol Chem 272:9802-8.

Pennell DJ, Carpenter JP, Roughton M, Cabantchik Z (2011) On improvement in ejection fraction with iron chelation in thalassemia major and the risk of future heart failure. J Cardiovasc Magn Reson 13:45. doi: 10.1186/1532-429X-13-45

Pham CG, Bubici C, Zazzeroni F, et al. (2004) Ferritin heavy chain upregulation by NF-kappaB inhibits TNFalpha-induced apoptosis by suppressing reactive oxygen species. Cell 119:52942. doi: 10.1016/j.cell.2004.10.017

Pitcher J, Abt A, Myers J, et al. (2014) Neuronal ferritin heavy chain and drug abuse affect HIVassociated cognitive dysfunction. J Clin Invest 124:656-69. doi: 10.1172/JCI70090

Pitcher J, Abt A, Myers J, et al. Neuronal ferritin heavy chain and drug abuse affect HIV-associated cognitive dysfunction. 1-14. doi: 10.1172/JCI70090DS1

Prusiner SB (1998) The prion diseases. Brain Pathol 8:499-513.

Prusiner SB (2013) Biology and genetics of prions causing neurodegeneration. Annu Rev Genet 47:601-23. doi: 10.1146/annurev-genet-110711-155524

Punta M, Coggill PC, Eberhardt RY, et al. (2012) The Pfam protein families database. Nucleic Acids Res 40:D290-301. doi: 10.1093/nar/gkr1065

Quintana C, Gutiérrez L (2010) Could a dysfunction of ferritin be a determinant factor in the aetiology of some neurodegenerative diseases? Biochim Biophys Acta 1800:770-82. doi: 10.1016/j.bbagen.2010.04.012

Rashid KA, Hevi S, Chen Y, et al. (2002) A proteomic approach identifies proteins in hepatocytes that bind nascent apolipoprotein B. J Biol Chem 277:22010-7. doi: 10.1074/jbc.M112448200

Richards TD, Pitts KR, Watt GD (1996) A kinetic study of iron release from Azotobacter vinelandii bacterial ferritin. J Inorg Biochem 61:1-13.

Roberts BR, Ryan TM, Bush AI, et al. (2012) The role of metallobiology and amyloid- $\beta$ peptides in Alzheimer's disease. J Neurochem 120 Suppl :149-66. doi: 10.1111/j.14714159.2011.07500.x

Rogers JT, Randall JD, Cahill CM, et al. (2002) An iron-responsive element type II in the 5'untranslated region of the Alzheimer's amyloid precursor protein transcript. J Biol Chem 277:45518-28. doi: 10.1074/jbc.M207435200 
Rouault TA, Tong W-H (2005) Iron-sulphur cluster biogenesis and mitochondrial iron homeostasis. Nat Rev Mol Cell Biol 6:345-51. doi: 10.1038/nrm1620

Rudeck M, Volk T, Sitte N, Grune T (2000) Ferritin oxidation in vitro: implication of iron release and degradation by the 20S proteasome. IUBMB Life 49:451-6. doi: $10.1080 / 152165400410317$

Sakamoto K, Iwasaki K, Sugiyama H, Tsuji Y (2009) Role of the tumor suppressor PTEN in antioxidant responsive element-mediated transcription and associated histone modifications. Mol Biol Cell 20:1606-17. doi: 10.1091/mbc.E08-07-0762

Santambrogio P, Biasiotto G, Sanvito F, et al. (2007) Mitochondrial ferritin expression in adult mouse tissues. J Histochem Cytochem 55:1129-37. doi: 10.1369/jhc.7A7273.2007

Santambrogio P, Cozzi A, Levi S, Arosio P (1987) Human serum ferritin G-peptide is recognized by anti-L ferritin subunit antibodies and concanavalin-A. Br J Haematol 65:235-7.

Santambrogio P, Levi S, Cozzi A, et al. (1996) Evidence that the specificity of iron incorporation into homopolymers of human ferritin L- and H-chains is conferred by the nucleation and ferroxidase centres. Biochem J 314 ( Pt 1:139-44.

Schmidauer C, Sojer M, Seppi K, et al. (2005) Transcranial ultrasound shows nigral hypoechogenicity in restless legs syndrome. Ann Neurol 58:630-4. doi: 10.1002/ana.20572

Sengupta R, Burbassi S, Shimizu S, et al. (2009) Morphine increases brain levels of ferritin heavy chain leading to inhibition of CXCR4-mediated survival signaling in neurons. J Neurosci 29:2534-44. doi: 10.1523/JNEUROSCI.5865-08.2009

Shi H, Bencze KZ, Stemmler TL, Philpott CC (2008) A cytosolic iron chaperone that delivers iron to ferritin. Science 320:1207-10. doi: 10.1126/science.1157643

Shi Z-H, Nie G, Duan X-L, et al. (2010) Neuroprotective mechanism of mitochondrial ferritin on 6hydroxydopamine-induced dopaminergic cell damage: implication for neuroprotection in Parkinson's disease. Antioxid Redox Signal 13:783-96. doi: 10.1089/ars.2009.3018

Singh A, Haldar S, Horback K, et al. (2013) Prion protein regulates iron transport by functioning as a ferrireductase. J Alzheimers Dis 35:541-52. doi: 10.3233/JAD-130218

Singh A, Isaac AO, Luo X, et al. (2009a) Abnormal brain iron homeostasis in human and animal prion disorders. PLoS Pathog 5:e1000336. doi: 10.1371/journal.ppat.1000336

Singh A, Kong Q, Luo X, et al. (2009b) Prion protein (PrP) knock-out mice show altered iron metabolism: a functional role for PrP in iron uptake and transport. PLoS One 4:e6115. doi: 10.1371/journal.pone.0006115

Singh A, Qing L, Kong Q, Singh N (2012) Change in the characteristics of ferritin induces iron imbalance in prion disease affected brains. Neurobiol Dis 45:930-8. doi:

10.1016/j.nbd.2011.12.012 
Singh N, Haldar S, Tripathi AK, et al. (2014) Brain iron homeostasis: from molecular mechanisms to clinical significance and therapeutic opportunities. Antioxid Redox Signal 20:1324-63. doi: 10.1089/ars.2012.4931

Snyder AM, Connor JR (2009) Iron, the substantia nigra and related neurological disorders. Biochim Biophys Acta 1790:606-14. doi: 10.1016/j.bbagen.2008.08.005

Snyder AM, Wang X, Patton SM, et al. (2009) Mitochondrial ferritin in the substantia nigra in restless legs syndrome. J Neuropathol Exp Neurol 68:1193-9. doi: 10.1097/NEN.0b013e3181bdc44f

Sofic E, Riederer P, Heinsen H, et al. (1988) Increased iron (III) and total iron content in post mortem substantia nigra of parkinsonian brain. J Neural Transm 74:199-205.

Sultana R, Boyd-Kimball D, Cai J, et al. (2007) Proteomics analysis of the Alzheimer's disease hippocampal proteome. J Alzheimers Dis 11:153-64.

Takahashi T, Kuyucak S (2003) Functional properties of threefold and fourfold channels in ferritin deduced from electrostatic calculations. Biophys J 84:2256-63. doi: 10.1016/S00063495(03)75031-0

Theil EC (2013) Ferritin: the protein nanocage and iron biomineral in health and in disease. Inorg Chem 52:12223-33. doi: 10.1021/ic400484n

Theil EC (2007) Coordinating responses to iron and oxygen stress with DNA and mRNA promoters: the ferritin story. Biometals 20:513-21. doi: 10.1007/s 10534-006-9063-6

Theil EC, Liu XS, Tosha T (2008) GATED PORES IN THE FERRITIN PROTEIN NANOCAGE. Inorganica Chim Acta 361:868-874. doi: 10.1016/j.ica.2007.08.025

Thompson K, Menzies S, Muckenthaler M, et al. (2003) Mouse brains deficient in H-ferritin have normal iron concentration but a protein profile of iron deficiency and increased evidence of oxidative stress. J Neurosci Res 71:46-63. doi: 10.1002/jnr.10463

Torti FM, Torti S V (2002) Regulation of ferritin genes and protein. Blood 99:3505-16.

Truty J, Malpe R, Linder MC (2001) Iron prevents ferritin turnover in hepatic cells. J Biol Chem 276:48775-80. doi: 10.1074/jbc.M105392200

Vanoaica L, Darshan D, Richman L, et al. (2010) Intestinal ferritin H is required for an accurate control of iron absorption. Cell Metab 12:273-82. doi: 10.1016/j.cmet.2010.08.003

Vanoaica L, Richman L, Jaworski M, et al. (2014) Conditional deletion of ferritin h in mice reduces B and T lymphocyte populations. PLoS One 9:e89270. doi: 10.1371/journal.pone.0089270

Vercellotti GM, Khan FB, Nguyen J, et al. (2014) H-ferritin ferroxidase induces cytoprotective pathways and inhibits microvascular stasis in transgenic sickle mice. Front Pharmacol 5:79. doi: 10.3389/fphar.2014.00079 
Vidal R, Miravalle L, Gao X, et al. (2008) Expression of a mutant form of the ferritin light chain gene induces neurodegeneration and iron overload in transgenic mice. J Neurosci 28:60-7. doi: 10.1523/JNEUROSCI.3962-07.2008

Wagstaff M, Worwood M, Jacobs A (1978) Properties of human tissue isoferritins. Biochem J 173:969-77.

Wang L, Yang H, Zhao S, et al. (2011) Expression and localization of mitochondrial ferritin mRNA in Alzheimer's disease cerebral cortex. PLoS One 6:e22325. doi:

10.1371/journal.pone.0022325

Wang PJ, McCarrey JR, Yang F, Page DC (2001) An abundance of X-linked genes expressed in spermatogonia. Nat Genet 27:422-6. doi: 10.1038/86927

Wang W, Knovich MA, Coffman LG, et al. (2010) Serum ferritin: Past, present and future. Biochim Biophys Acta 1800:760-9. doi: 10.1016/j.bbagen.2010.03.011

Wardeska JG, Viglione B, Chasteen ND (1986) Metal ion complexes of apoferritin. Evidence for initial binding in the hydrophilic channels. J Biol Chem 261:6677-83.

Watt GD, Jacobs D, Frankel RB (1988) Redox reactivity of bacterial and mammalian ferritin: is reductant entry into the ferritin interior a necessary step for iron release? Proc Natl Acad Sci U S A 85:7457-61.

Weiss A, Brill B, Borghouts C, et al. (2012) Survivin inhibition by an interacting recombinant peptide, derived from the human ferritin heavy chain, impedes tumor cell growth. J Cancer Res Clin Oncol 138:1205-20. doi: 10.1007/s00432-012-1195-1

Wu W-S, Zhao Y-S, Shi Z-H, et al. (2013) Mitochondrial ferritin attenuates $\beta$-amyloid-induced neurotoxicity: reduction in oxidative damage through the Erk/P38 mitogen-activated protein kinase pathways. Antioxid Redox Signal 18:158-69. doi: 10.1089/ars.2011.4285

Wypijewska A, Galazka-Friedman J, Bauminger ER, et al. (2010) Iron and reactive oxygen species activity in parkinsonian substantia nigra. Parkinsonism Relat Disord 16:329-33. doi: 10.1016/j.parkreldis.2010.02.007

Yanatori I, Yasui Y, Tabuchi M, Kishi F (2014) Chaperone protein involved in transmembrane transport of iron. Biochem J. doi: 10.1042/BJ20140225

Yang X, Arosio P, Chasteen ND (2000) Molecular diffusion into ferritin: pathways, temperature dependence, incubation time, and concentration effects. Biophys J 78:2049-59. doi: 10.1016/S0006-3495(00)76752-X

Yang X, Cohen M V, Downey JM (2010) Mechanism of cardioprotection by early ischemic preconditioning. Cardiovasc Drugs Ther 24:225-34. doi: 10.1007/s10557-010-6236-X

Yuan X, Cong Y, Hao J, et al. (2004) Regulation of LIP level and ROS formation through interaction of H-ferritin with G-CSF receptor. J Mol Biol 339:131-44. doi: 10.1016/j.jmb.2004.03.027 
Zarjou A, Bolisetty S, Joseph R, et al. (2013) Proximal tubule H-ferritin mediates iron trafficking in acute kidney injury. J Clin Invest 123:4423-34. doi: 10.1172/JCI67867

Zecca L, Berg D, Arzberger T, et al. (2005) In vivo detection of iron and neuromelanin by transcranial sonography: a new approach for early detection of substantia nigra damage. Mov Disord 20:1278-85. doi: 10.1002/mds.20550

Zecca L, Youdim MBH, Riederer P, et al. (2004) Iron, brain ageing and neurodegenerative disorders. Nat Rev Neurosci 5:863-73. doi: 10.1038/nrn1537

Zhang Y, Mikhael M, Xu D, et al. (2010) Lysosomal proteolysis is the primary degradation pathway for cytosolic ferritin and cytosolic ferritin degradation is necessary for iron exit. Antioxid Redox Signal 13:999-1009. doi: 10.1089/ars.2010.3129

Zhao G, Bou-Abdallah F, Arosio P, et al. (2003) Multiple pathways for mineral core formation in mammalian apoferritin. The role of hydrogen peroxide. Biochemistry 42:3142-50. doi: 10.1021/bi027357v

Zieger MAJ, Gupta MP (2009) Hypothermic preconditioning of endothelial cells attenuates coldinduced injury by a ferritin-dependent process. Free Radic Biol Med 46:680-91. doi: 10.1016/j.freeradbiomed.2008.12.004

Zumbrennen KB, Wallander ML, Romney SJ, Leibold EA (2009) Cysteine oxidation regulates the RNA-binding activity of iron regulatory protein 2. Mol Cell Biol 29:2219-29. doi: 10.1128/MCB.00004-09 
